\title{
SPEECH ADDRESSED TO CHILDREN: ISSUES AND CHARACTERISTICS OF PARENTAL INPUT
}

\author{
James Earle Landes \\ University of Michigan
}

\begin{abstract}
The linguistic environment of the child was largely taken for granted by the generative grammarians of the 1960's because of their emphasis on innate ideas as a basis for first language acquisition. Only recently have researchers studied the child's environment linguistically, indicating that not only are adults sensitive to and affected by the need to communicate with their children, but that interaction patterns between parent and child change according to the increasing language skill of the child. These interaction patterns are linguistically summarized here in terms of their syntactic and stylistic features. Such features include sentence complexity, number of transformations involved, types of sentences addressed to the child, the use of repetition, modeling, correcting, baby talk register, and the speed of delivery. All of these features are correlated with the age of the child, but many relationships are still unexplored and questions unresolved. If the current trend of research continues, our outlook on the role of parental input in the process of first language acquisition may change quite drastically.
\end{abstract}

Contemporary emphasis on innate universal principles as a basis for language acquisition (Lenneberg 1964, 1967; McNeill $1966,1968,1970$ ) has devalued the contribution of parental input to the acquisition process. Yet the fact that the speech young children hear is their only source of information about the language they learn, must be taken into account in any explanation of the process of first language learning. While the majority of naturalistic studies focused on what children have to say, ironically, few attempted to study the language directed towards them. The assumption that children hear a random, often ungrammatical sample of adult utterances (MacClay and Osgood 1954, Bever, Fodor and Weksel 1965), has served as a cornerstone in support of the view that infants must be preprogrammed for the task of language learning. Such an assumption is not only naive, it is unbased in fact. "The ungrammaticality of everyday speech," wrote Labov, "appears to be a myth with no basis in actual fact. In the various empirical studies that we have conducted, the great majority of utterances-about $75 \%$-are well formed sentences by 
any criterion. When rules of ellipsis are applied, and certain universal editing rules to take care of stammering and false starts, the production of truly ungrammatical and ill-formed sentences falls to less than two percent." (Brown 1973:387 quoting Labov). Brown and Bellugi (1964) noted that sentences addressed to children were especially grammatical; Drach (1969) observed that speech to children lacked hesitations, false starts, and errors. Waterson (1971) found neither phonological nor grammatical deviance common, and Halliday (1972) found support for Labov's statement.

If input is indeed random, then children should be able to sit before the television or radio and discover the structure of language. While such a case has occurred, it was with unhappy results. Ervin-Tripp (1971) commented on a case involving two hearing children, born of deaf parents, who watched a great deal of television, yet at age three were unable to understand or produce speech at all. Apparently viewing quiz shows or the late movie isn't quite sufficient, nor is speech likely to be acquired if both parents speak solely in abstract, philosophical dialogues in the presence of the infant. Enough investigations have been conducted to conclude safely that the speech mothers direct towards their infants is hardly what they use with their husbands. And although this surely comes as no surprise to anyone, the characteristics of adult linguistic input are quite interesting in themselves and vary stylistically in accordance with the age of the child.

Before reviewing current knowledge about the language addressed to children, it is of interest to view the acquisition process from the perspective of generative grammar, a theoretical position that is radically different from traditional learning theory. Prior to the advent of transformational linguistics, American psychologists ascribed primary importance to the role of parental input, suggesting that from imitation, the child acquired a number of stimulus-response connections between verbal labels and salient features of his environment. Once these labels were acquired, the child attached them with other words in sequences and ordering or structuring began. Since then, researchers like Lenneberg and McNeill have suggested that only a minimum of language input from the environment is necessary for normal linguistic development, since the so called linguistic universals were innately represented in the structure and functioning of the human nervous system and articulatory apparatus. This argument (McNeill 1966, 1968,1970 ) holds that parental input "serves the function of 
helping a child to choose among a narrow set of possibilities defined by the linguistic universals" (1966:65). Drawing attention away from linguistic input, McNeill emphasized the importance of the language acquisition device (LAD).

McNeill further devalued the role of linguistic input in stating that "...the speech of adults from which a child discovers the locally appropriate manifestation of the linguistic universals is a completely random, haphazard sample, in no way contrived to instruct a child on grammar" (McNeill 1966:73). If such is true, then a tremendous amount of language specific structure must be attributed to the nervous system of the new-born infant. As outlined in Figure 1, the input for the generativist is the corpus, which according to McNeill "... is a set of utterances, some grammatical, some not. The corpus may be large but it is not unlimited in size. It contains, let us say, the number of utterances ordinarily overhead by a two year old child" (1966:23). This corpus of occurring speech belongs to the performance side of the competence/performance dichotomy, and the child's task is to segment utterances, abstract surface structures, and arrive at deep structures and rules which form the basis of his competence.

McNeill further proposed that children had an innate knowledge of at least two aspects of linguistic structure: 1) a universal hierarchy of grammatical categories, and 2) a knowledge of the basic grammatical relations, including such concepts as "subject of a sentence-predicate of a sentence", "main verb of a predicte phrase-object of a predicate phrase", and "modifier of a noun phrase-head noun of a noun phrase". McNeill's position then, is that it does not matter greatly what kind of linguistic input the child is exposed to, as long as it is a natural language, because as LAD receives a certain amount of linguistic data it will scan it for distinctions that match the distinctions drawn in the universal hierarchy of categories. "Because LAD is exposed to a natural language, some of the universal distinctions are bound to

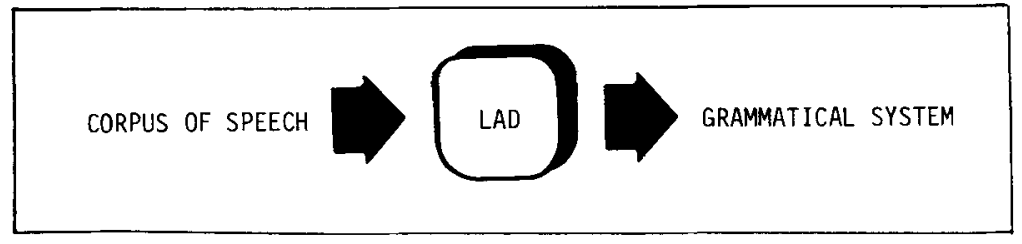

Figure 1. McNeill's model of an abstract "Language Acquisition Device". 
be present. Thus, we can imagine that whenever LAD observes such a distinction in the preliminary linguistic data, it is incorporated into LAD's own version of the underlying grammar. The function of the preliminary data, therefore, is to give LAD a basis for selecting among various universal distinctions" (1966:49). Although McNeill's model is simple in design, it reflects an extremist attitude in its lack of focus on exactly what the corpus or input entails, and equally importantly, on what the child's task involves as he progresses through the various stages of first language acquisition.

Thus, the first addition that might be made in McNeill's model is to differentiate between the concepts "adult linguistic input" and "child linguistic intake" (See Figure 2). Before attempting to specify what adult linguistic input to children involves, it is convenient to think of a series of filters through which any message or input must pass before reaching its destination, in this case, the child. These filters are both syntactic and stylistic and are governed by both objective and subjective factors. An adult adjusts his syntactic and stylistic choices according to the requirements of the context but at the same time preserves some of the individuality and idiosyncrasy that distinguishes him from other speakers. The subjective factors of selection that the adult brings to the communication process include such things as frequency of verbal preference and perhaps a

\section{INPUT FILTERS}
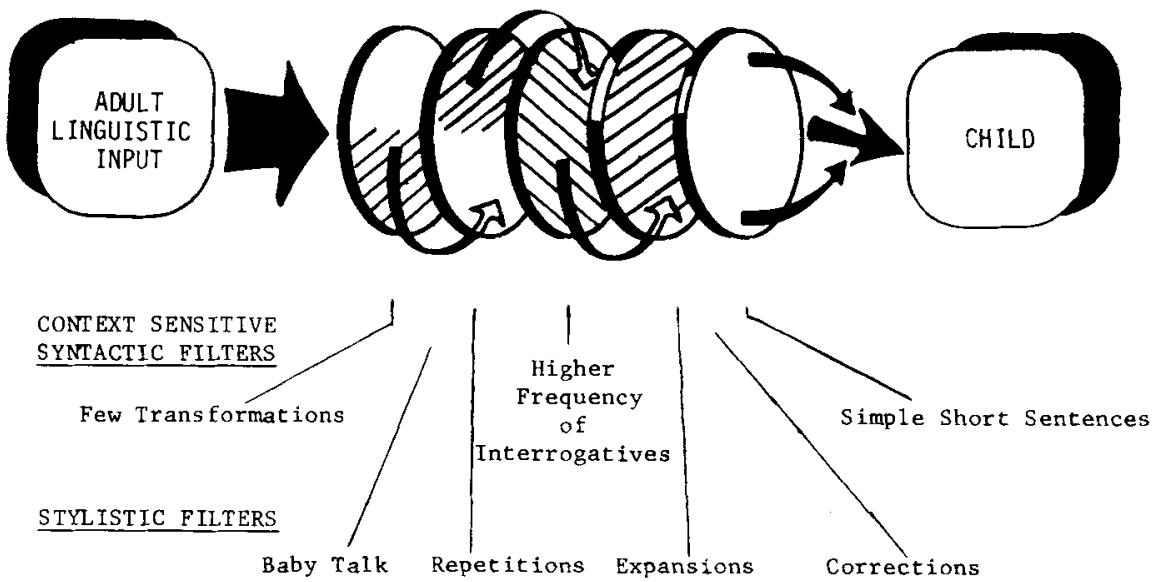

Figure 2. Input Filters. 
series of subjective factors of selection that involve the mental type of the speaker and his skill with language. Objective factors of selection are independent of the speaker, though they exercise their influence through him and result in the creation of what I term "context sensitive filters." Such filters would include all those devices used for the benefit of the child, or because a child is the one being addressed. These filters include imitation, an acceptable device in adult/child interaction, but unused in adult speech unless mockery is intended. Likewise, baby-talk is context sensitive as it is applied to children and highly restricted among adults.

Input filters, to be described in detail, change in form and frequency over time as does the child's linguistic intake. That is to say, linguistic intake likewise does not remain stable as the child matures to attend to more of his verbal environment and to recognize more of the vocabulary around him as his memory capacity expands and other cognitive abilities develop.

In what is perhaps the earliest study of infant reaction to input, Kagan and Lewis (1965) found that infants between 6 and 13 months reacted with cardiac deceleration and less activity to music than to the human voice. Generally, there was more vocalization in reaction to the female voice than to other signals, and an increase in vocalization during the rest period in response to female voices suggested a "speaking after listening" behavior. Kagan and Lewis concluded that human speech has already acquired psychological significance for infants at this age. Later, Lewis, Kagan and Campbell (1966) observed that there was a greater decrease in arm movement in response to the mother's "hello" than to a strange male or female's voice. Such results led to the tentative conclusion that a mother's voice could be differentiated from that a stranger's, and that word length utterances were possibly preferable to continuous speech. Although our knowledge about linguistic intake is still rudimentary, what is suspected about it is summarized schematically in Figure 3 as additions to the simple flow diagrams of earlier figures.

Syntactic input to children is generally characterized as simplistic, involving few transformations, numerous interrogatives, and short sentences which are more clearly articulated and have exaggerated stress and intonation. In the Berkeley studies on the structure of input to children, Drach (1969) found twice as many transformations per utterance in speech among adults as compared to an adult addressing a child of two years, two months. Moreover, there were ten times as many subordinate clauses in adult speech as opposed to the adult/child sample. "In the A-A (Adult/Adult) 


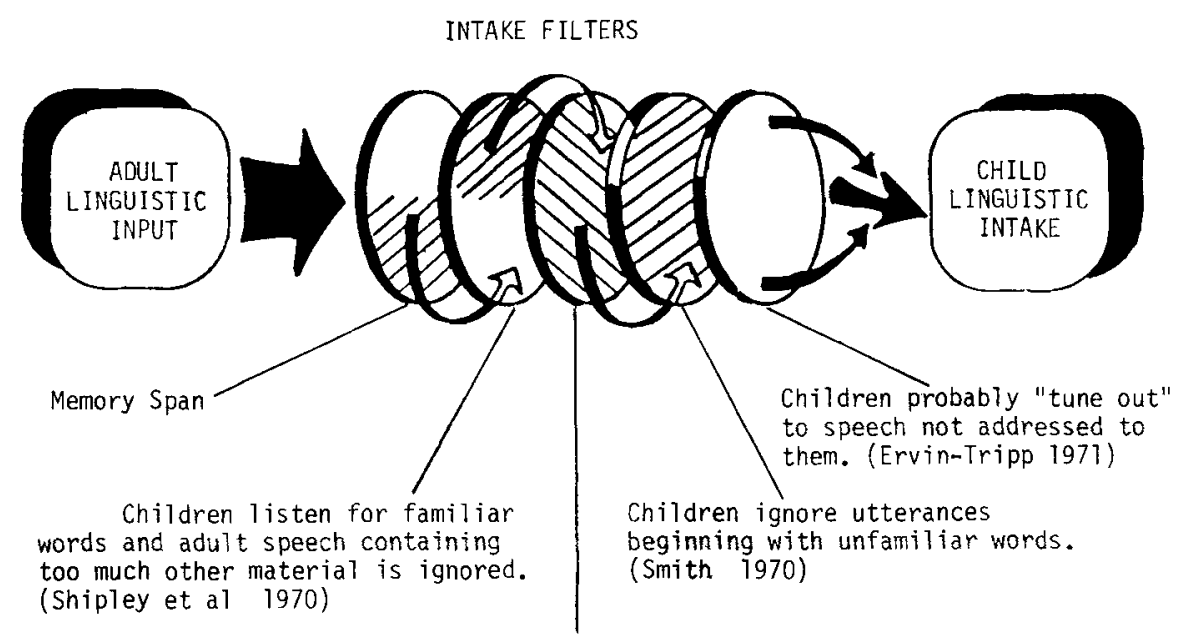

Between 3 and 13 months human speech acquires psychological significance and the mother's voice can be differentiated from strangers. (Kagan, Lewis and Campbell 1965-66)

Figure 3. Intake Filters.

sample there were 90 such constructions, while there were only 9 in the A-C (Adult/Child) sample" (1969:8). This early study supports the notion characterizing parental input as simple in terms of the few transformations involved and a general lack of subordination. But later studies support this, as when Snow (1972) found complexity as a measure in MLU, preverb length, and sentence complexity, greater for ten year olds than for two year olds.

Sentence complexity scores were lower in the 2-year old present condition, indicating less use of subordinate clauses and compound verbs.... Mothers used fewer subordinate clauses and compound verbs when speaking to young children.... Mean preverb-length scores were lower, indicating less left branching and selfembedding.... About $16 \%$ of the utterances spoken to 2 year olds were simple phrases, which were not produced on the basis of a subject-verb rule. This is quite a high percentage for a child who will have to deduce subject-verb rules for producing sentences. (Snow 1972:561)

Phillips (1973), whose results generally support Snow's conclusions on syntactic complexity, observed that it is still unknown at exactly what age speech addressed to children reaches 
its adult level. Snow's data on speech addressed to ten year-olds suggested a compatibility in syntactic complexity to language addressed to adults. Thus, by age ten, the child is apparently being addressed as an adult, but exactly what goes on from ages one through ten is still somewhat a mystery. Phillips (1973) later noted that mothers seemingly did not speak more simply to children of 8 months than they did to children of 18 months. There may be some conformity of input between these ages, though this is hard to believe. In the Harvard studies of Adam, Eve, and Sarah, Pfuderer (1969) found Adam at Stage I being addressed with $94 \%$ simple sentences and $5 \%$ complex sentences, while at Stage III the frequency of simple sentences decreased to $80 \%$ and complex sentences rose to $19 \%$. At Stage I, Eve was addressed with $96 \%$ simple sentences and $3 \%$ complex sentences. By Stage III the simple sentences addressed to her had decreased to $73.5 \%$ while complex sentences rose to $25 \%$. Percentages for Sarah fluctuated very little, being addressed with $95 \%$ simple sentences and 6\% complex sentences at Stage I, at Stage III she was addressed with $90 \%$ simple and $9 \%$ complex sentences. Percentages of complex sentences in adult/adult speech analyzed by Pfuderer was $14 \%$. Therefore, Adam and Eve reached levels comparable to adult speech by the ages of $2-1 / 2$ and 3 , although neither attained adult percentages of input for passives or other sentence types such as negatives.

In a comparison of teachers addressing kindergarten children of 5 and 6 years of age, and teachers addressing each other, Granowsky and Krossner (1970) found that a mean of $61.6 \%$ of adult/child speech contained simple sentences, while adult/adult speech contained $37.7 \%$ simple sentences. Adult/child speech contained $2.9 \%$ compound sentences, $26.1 \%$ complex, and $2.4 \%$ compound-complex sentences. Similar findings for adults were $9.2 \%$ compound, $33.2 \%$ complex, and $15.5 \%$ compound-complex. These authors note a greater percentage in usage of simple sentences $(61.6 \%)$ than compound and complex ones combined (29\%).

Frequency of sentence type, as linguistic input, has been investigated in several studies, sometimes with contradictory results. Pfuderer (1969), in an analysis of eighteen hours of adult/child speech in the records of the Harvard children, found a dominance of simple sentences: $94-96 \%$ at Stage I of which roughly $50 \%$ were simple active affirmative declaratives for all children between Stages I-III, 20-35\% were interrogatives, and $5-20 \%$ were negatives between these stages. The percentage of 
complex sentences from Stages I-III were between 3 and $25 \%$, of which $2-10 \%$ were complex active affirmative declaratives, $1-7 \%$ were questions, and $2-8 \%$ were negatives. Passive sentences addressed to these children ranged from $0-1.5 \%$ during these stages. In the later records of Adam and Eve there is a marked rise in the complex sentence types, the percentage climbing toward a figure more typical for adult/adult speech.

Drach (1969), in an analysis of 111 sentences of a Black mother addressing her 26 month old son, found 34 imperatives in the adult/child interaction, while in a similar corpus of the same number of sentences with the mother addressing a friend, only two imperatives occurred. Negatives were reportedly rare in adult/child speech, agreeing with Pfuderer's findings, but frequent among adults. A striking difference between adult and adult/child speech was the number of questions Drach found. In the adult corpus of 111 sentences, there was only one clear-cut question, while there were a total of 57 questions in the adult/child sample, that is, approximately half the sentences addressed to the child were questions. Ervin-Tripp (1970) emphasized that high percentages of questions in adult/child speech suggests that this type of speech is probing for feedback. She later stated that 25-50\% of a mother's speech addressed to a two year-old are questions, while in samples of informal family conversations among adults, the range was from $1-25 \%$.

Such a preponderance of interrogatives and imperatives in adult/child speech coincides with Blount's (1972) findings of Luo and Samoan adults. Blount found in Kernan's (1969) data on Samoan that the speech addressed to Sapili, a 21/2 year-old child, contained $72.1 \%$ interrogatives, $13.4 \%$ imperatives, and $14.5 \%$ declaratives. Blount's own data on parental speech addressed to two Luo children of $2^{1 / 2}$ years of age contained $95 \%$ interrogatives, 2.5\% imperatives, and 2.5\% declaratives for Rabuogi. Percentages for the other child, Akinyi, were $46.3 \%$ interrogatives, $43.3 \%$ imperatives, and $10.4 \%$ declaratives. Speculating that during the day's activities, the percentage of declaratives remains low, imperatives become almost as important as interrogatives. In contrast, a sample of adult/adult speech contained $69.2 \%$ declaratives, $15.6 \%$ interrogatives, and $14.3 \%$ imperatives. Explaining this predominance of non-declarative sentences in the adult/child interaction, Blount suggests that the normal function of the adult/child relationship is to manage or influence the child's behavior. "The children are not regarded as conversational partners, and consequently, the input speech shows a high percentage of 
interrogatives, a lower percentage of imperatives, and a still lower percentage of declaratives" (1972:124). Regarding this high percentage of interrogatives, Blount found adults asking only the kinds of Wh-questions that the children could handle at their particular stage of development. Two children, the Samoan Sapili and the Luo Akinyi, were asked mainly labeling questions, that is, who and what questions. The third child, Rabuogi, whose speech was somewhat more advanced than Sapili's or Akinyi's, was asked who, what, where, and yes-no questions, the latter two of which made up $50 \%$ of his input of interrogatives.

The striking difference between Pfuderer and Drach (1969) and Blount, that is, $50 \%$ declaratives in the American studies versus $2-14 \%$ declaratives in the Samoan-Luo study, and 20-30\% interrogatives in the American studies versus $72 \%$ interrogatives in Samoan and $46-95 \%$ in Luo, may be due to the level of analysis involved. Pfuderer counts the number of questions asked at each stage of development for Adam, Eve, and Sarah, while Blount considered the kinds of questions being asked. Blount demonstrated that the percentage of questions can remain stable while the content of them is tailored to the child's stage of linguistic development. Blount writes: "The low incidence of Wh-questions in the American sample may result from the absence of a testing environment, i.e. one in which the child's role is subordinate... Asking a child to express his opinion in Luo society is a rare phenomenon, and requesting him to be a playmate with an adult is even less common. The American child was, in short, allowed more behavioral latitude in the conversation than were the Samoan or Luo children" (1972:127). Although tailoring of input for children appears to be universal, what is selected and what is emphasized may be culturally specific, just as later we shall see that parental input, however important it appears to American culture, is not typical of the type of input that many children receive around the world.

In the pilot study comparing a Black mother's speech to another adult with her speech to her 26 month old son, Mark, Drach (1969) found striking dissimilarities regarding utterance length. Morpheme counts showed adult/adult speech more variable in length, with an average length $2 \frac{1}{2}$ times as great as adult/child speech. Snow (1972) found 2 year-olds were addressed in shorter and grammatically simpler utterances than 10 year-olds. Fraser and Roberts (1973), in an analysis of the variations in speech to preschool children from $1 \frac{1 / 2}{2}$ to 6 years of age, found in a task involving telling a story from pictures, a clear increase in MLU 
from $1^{1 / 2}$ to $2^{1 / 2}$ years of age with no change thereafter. Granowsky and Krossner (1970) examined sentence length among adults, and adults addressing kindergarten children between the ages of 5 and 6 . Their results showed that mean sentence length in adult speech was 13.50 words, while for adult/child speech it was 8.17 words. When the percentage of sentences in each sample containing fifteen words or more was calculated, $35 \%$ of the total number of sentences among adults and $13 \%$ of the sentences addressed to children were fifteen words or longer.

Moerk (1974) found a high correlation between a mother's average statement length with the age and average statement length of her child. In a detailed study of five children ranging from 1:8 to 5:0 years of age, the average statement length of the mothers lay above the average statement length of the children. Moreover, the maximum length of the children's statements was above the mean length of the mother's statements. "This proves that children can even produce statements of greater length than they hear on the average in their environment" (Moerk 1974:107). Moerk suggested that mothers follow various strategies in their interaction with their children, noting that two of the mothers under study differed by only 4 syllables in maximum statement length to 2.4 and 3.4 year-olds, while two other mothers differed by 15 syllables in addressing a 2.6 and a 5 year-old.

The syntax of the language spoken to children has been of ancillary interest to a few of the naturalistic studies of the past decade. The studies of Bowerman and Bloom touch upon the topic, but not in great detail. Bowerman (1973) presented evidence that Seppo and Rina were sensitive to the word order patterns of their mothers and had learned the important characteristics of Finnish dominant word order. The most frequent pattern of Seppo's mother was $\mathrm{S}+\mathrm{V}$, with $\mathrm{S}+\mathrm{V}+\mathrm{O}$ second most frequent. These were the most and second most frequent patterns for Seppo. Likewise, Rina had learned both the dominant and most frequent alternative orders modeled by her mother. Bowerman observed: "The correspondence between the relative frequencies with which the Finnish children and their mothers produced various word orders... makes it difficult to accept Slobin's hypothesis that children's apparent tendency to use fixed word order results from the operation of the innate language acquisition device and minimizes the contribution of linguistic input..." (Bowerman 1973:165). Later Bowerman wrote:

Finally, the Finnish data challenge McNeill's argument that 'rigid order is precisely what would be expected on the hypothesis that 
children include abstract features (basic grammatical relations) in their early speech, but must add to this inborn structure the particular transformations employed in their native language.' (1966) If Seppo was indeed trying to express the basic grammatical relations, he evidently did not feel that order, in the initial absence of inflections, was indispensable to this end. (Bowerman 1973:165-166)

Bloom (1970), not reporting on the mother/child interaction, stated early in her work that: "The mothers were present less than one third of the time and the fathers only occasionally" (Bloom 1970:16). Moreover, Bloom was unworried over frequencies of parent/child speech as no frequencies are reported. Although these two features are strikingly missing, Bloom does state that: "The results of this study have confirmed the observations of other investigators (Brown and Fraser 1963, McNeill 1966) that children's language is directly related, from the beginning, to the adult model and is not an exotic language that is eventually supplanted by a different system" (Bloom 1970:225). However, when highlighting individual differences in language development between the children studied, Bloom makes what must be interpreted as a criticism of the generative linguistic viewpoint:

It appears that the results of this study would cast some doubt on the view of language development as the same innately preprogrammed behavior for all children. The emerging grammars proposed for the language of the three children were different; a single grammar would not have accounted for the language of all three in any adequate way. (Bloom 1970:227)

The thrust of Bloom's study was on reaching the "meaning" of children's utterances by focusing on the correlation of linguistic and contextual features. Indeed, Bloom seemed more interested in this relationship and the relationships between these children than in what was occurring as parental input. Table 1 summarizes the characteristics of syntactic input as a function of age.

The second major concern of this paper involves stylistic elements of parental input, which would not be perceived if they were random or without a code of reference. It is useful, therefore, to first use adult speech as the norm in seeking the variations in adult/child interactions, then to examine what may be termed "training sessions" as the mother employs a variety of strategies or devices in dealing with her child, and finally, to allow context to be the norm in examing what Moerk terms "behavior-situation units". Such units, or verbal behavior episodes, often appear as a problem, topic, or theme, and the interaction between mother and child proceeds smoothly until a solution is reached. It is at this 
TABLE 1

Characteristics of syntactic input as a function of age

$\begin{array}{lll} & \begin{array}{c}\text { Age } \\ \text { (in } \\ \text { Months) }\end{array} \quad \text { Frequency of Type } \\ \text { Sentence Complexity } & \text { M }\end{array}$

*No difference in sentence complexity $1_{18}^{8}$ observed. (Phillips 1973)

* $16 \%$ of the utterances addressed to 2 year-olds were simple phrases. (Snow 1972)

*Harvard children addressed with $94-96 \%$ simple sentences Stages I-III (24-36 mos.)

*Harvard children addressed with $3-25 \%$ complex sentences Stages I-III. (Pfuderer 1969)

* Child addressed with $1 / 2$ as many transformations as adults and one tenth the number of sub. ordinations.

* Adult speech has $2^{1 / 2}$ as many morphemes/utterance compared to adult/child speech. (Drach 1969)

*6.9\% Adult/Child speech contained sentence fragments. Average MLU, 8.17 words per utterance. (Granowsky \& Krossner 1970)

*'Ten year old child addressed with syntactic complexity comparable to an adult. (Snow 1972)
MARK

$50 \%$ simple active declaratives $20-30 \%$ interrogatives 10-20\% negatives (Drach 1969)

$30 \quad$ SAPILI

13.4\% Imperatives (Samoan)

$14.5 \%$ Declaratives

AKINYI

46.3\% Interrogatives

43.3\% Imperatives

10.4\% Declaratives (Luo)

RABUOGI

95\% Interrogatives

2.5\% Imperatives

2.5\% Declaratives

KINDERGARTEN STUDY

Years $\quad 61.6 \%$ Simple sentences

2.9\% Compound sentences

21.6\% Complex sentences (Granowsky \& Krossner 1970) 
point that the child is granted status as one whose remarks are worthy of interest and justify a verbal response.

When adult speech is taken as the norm, then a slower pace of speech in addressing children, lexical choice, and baby talk are three striking variables. Drach (1969) found adult speech significantly faster than adult/child speech. This is documented by Broen (1971) in a study comparing a mother's speech to her own children aged 2 to 5 , and to another adult where it was found that mothers talked to 2 years-olds more slowly, with more pauses at the ends of utterances, and with fewer disfluencies than when talking with adults. Later Broen (1972) found that mothers addressed 21 month olds with an average of 69.2 words per minute and addressed 5 year olds with 86.2 words per minute, while addressing other adults in conversation with 132.4 words per minute. Brown, Salerno and Sachs (1972), report on an experiment involving five young adults with no children of their own who were asked to tell a story about a picture to a twenty-two month old child, then to an adult female. In addressing the child, adults spoke more slowly.

Regarding lexical choice, only two studies, Drach (1969) and Granowsky and Krossner (1970) have calculated type-token ratios as a measure of vocabulary diversity addressed to the child. This score is the number of different words divided by the square-root of twice the number of words in the sample. In Drach's study, type-token ratios calculated for adult and adult/child samples were .282 and .207 respectively. Drach concluded that the mother used a greater variety of lexical items when speaking with other adults than she did when speaking to her 26 month old son. Granowsky and Krossner found a mean type-token ratio score of adult/adult speech to be 6.68 and a mean type-token ratio score for adult/child speech to be 5.06. Such figures are interesting to compare with the results of Blodgett (1968) who found that the average type-token ratio score of the speech of middle to upper class 4 year-olds was 5.19 while discussing pictures with an adult. This seems to imply that adults in addressing kindergarteners in a classroom, constrain themselves to the level of the speech of the children they are addressing. Brown (1958) once remarked that adults believe that children have trouble pronouncing long names and so should always be given the shortest possible names, that a word is preferable to a phrase, and among words a monosyllable is better than a polysyllable.

Viewing the language spoken to children as a special speech style or code, Ferguson (1964) observed that baby-talk is one of 
many speech acts persisting from generation to generation. Unrestricted to the adult/child interaction, Berko-Gleason (1973) reported that children by the age of eight have control of the style in their dealings with younger children. It is therefore not surprising that adults who are not parents, also control the style. This is confirmed by two experimental studies. Brown, Salerno and Sachs (1972) reported that five young adults, all of whom had some contact with children, were observed to change their speech style when talking with young children with whom they had no previous contact. Likewise, Snow (1972) reported that women who had little experience with children modified their speech when preparing tapes intended for two year-olds. Although non-mothers modified their speech slightly less than mothers in that situation, differences were insignificant.

Frequency of usage no doubt depends on those involved, yet Ervin-Tripp (1971) claimed baby-talk to be a brief style, uncharacteristic of most of the mother/child interaction. The style itself has been characterized by three kinds of material: 1) a set of words peculiar to the style; 2) a subset of the language's normal intonational and paralinguistic phenomena; and 3) phonological and grammatical modification of the normal language. Ferguson supplies such data from six languages for such things as kin-terms, body parts and functions, basic qualities, animals, and games. Each language has a canonical form which predominates in its baby-talk, usually $\mathrm{CVC}, \mathrm{CVCV}$, or $\mathrm{CVCCV}$, and reduplication of syllables or whole words is common. Support for these findings may be found in Casagrande's (1964) study of baby-talk in Comanche and in Week's (1973) study of eight words she elicited with great difficulty from the Yakima Indians of Central Washington.

In what may be termed "training sessions", mothers employ a variety of strategies or devices in dealing with their children. These include repeating the input, prodding, modeling, correcting, and expanding the child's output. A device with theoretically possible accelerating effects on language acquisition is the repetition of input. Kobashigawa (1969), studied the same corpus examined by Drach, the speech of a Black mother to her 26 month old son, and found that $15 \%$ of her statements, $25 \%$ of her questions, and $60 \%$ of her imperatives were repeated. Instances of repetition occurred relatively soon after the original utterance, and "soon" meant that there were no prolonged pauses with intervening activity. Repetition sometimes occurred when it seemed unreasonable to expect the child to understand what was said in the first 
place, but repetitions did not tend to be simpler than the originals. Kobashigawa found repetition to constitute $34 \%$ of all utterances and that it was common to maintain the same message across several sentences varying only minor features which did not alter meaning such as intonation rate, word order where non-critical, or optional deletions and contractions.

Snow (1972) found repetition of complete sentences three to four times as frequent for 2 years-olds as for 10 year-olds. Pending on the task, $3-8 \%$ of the utterances addressed to 2 year-olds were repeated shortly afterwards. "Short term memory limits the time available for processing input. Repetition of a sentence would give added processing time, thus increasing the child's chances of successfully processing the sentence" (Snow 1972:563). Snow later states that in her first experiment, $14 \%$ of the mother's utterances to 2 year-olds were paraphrases of earlier utterances. "For example: "Give mummy all the red toys. I would like all the things that look like this. Can you give me all the red things?" (Snow 1972:563). This is three times as many repetitions as supplied for 10 year-olds.

In a study of children ranging in age from 2.2 to 5 years, Moerk (1974) found systematic changes in interactions of mothers and their children. Mothers proved sensitive to the language capabilities of their children and adapted verbal utterances to these capacities. Moerk found instances of "prodding" as one form of early interaction between mother and child. "Prodding" is the term used for instances when the mother makes it verbally clear that she wants her child to say or repeat something. Such invitations usually begin with "Can you say '...?" or "Say '...". After the prodding statement, the mother may model the word she wants the child to repeat. Although "prodding" was never a frequent form of interaction at any particular stage, it did become nonexistent in the interactions with older children.

Modeling, as another form of parental input, has been discussed extensively by Brown $(1970,1973)$. One aspect Brown studied was the variation in frequency with which particular constructions were produced or "modeled". In 1973 he wrote: "Thus far we have no evidence whatever that parental frequency of usage is a determinant of acquisition order, neither frequencies of usage in general parent-to-child English nor the individual frequencies found in samples of individual households" (Brown 1973:364). Although frequency may be an insignificant variable in the acquisition of morphemes, it seems significant to the acquisition of prepositions: "for any given preposition, both the 
frequency with which it is modeled and the frequency of expansions are strongly related to the point at which that preposition is regularly supplied by the child in all the phrases requiring it" (Brown 1970:146). In its purest form, modeling does not include repetition of lexical items, but in practice modeling usually repeats the lexical items of the previous utterance. Often an expansion, then a modeled statement, follows a child's utterance. In a narrower sense, modeling has been used to refer to only those instances when it is evident from the situation that the mother intends to demonstrate or teach her child something. This is often apparent when the child does not know the name of an animal in a picture book and the mother provides the name. Moerk (1974) found modeling of picture books to diminish as the child reached $2^{1 / 2}$ years but modeling in general increased to about $70 \%$ of the total adult/child interaction by $3^{1 / 2}$.

Moerk also discovered a high percentage of corrective feedback at age two which steadily diminished until it reached zero at age five. By "corrective feedback", Moerk included phonetic and semantic, as well as grammatical corrections, supplied by the mother after an incomplete or incorrect statement by her child. Such feedback may appear in the form of an expansion or reduction of the child's sentence. Generally, most studies devalue the role of corrective feedback, placing little emphasis on it. Roger Brown (1973) stated that parents generally corrected pronunciation, nasty words, and regularized irregular allomorphs like digged or goed. But as for syntax, mistakes such as "Why the dog won't come?" never register and are even sometimes modeled by the adult. Braine (1971:159) reported on such an interaction between a mother and her 26 month old son: "Stevie complains to his mother about his elder brother, Tommy, and says "Tommy fall Stevie truck down.' His mother then responded with: "Tommy, did you fall Stevie's truck down?"' McNeill (1966) maintained that there was little to indicate that young children were able to use such information even when it was given. Reporting on an interaction between mother and child, the child was reported to say: "Nobody don't like me." to which the mother replied: "No, say, "nobody likes me." The child then repeated: "Nobody don't like me." and the dialogue was repeated eight times (McNeill 1966:69).

Brown and Hanlon (1970) made similar observations, finding that corrections were made primarily on the truth-value of statements. Brown, Cazden and Bellugi (1969) noted that it seems to be truth value rather than syntactic well-formedness that chiefly 
governs explicit verbal reinforcement by parents. This is somewhat paradoxical to the fact that the usual product of such a training schedule is an adult whose speech is highly grammatical but not notably truthful. Ervin-Tripp (1971) makes identical observations as does Claudia Mitchell, the fieldworker for Drach and Pfuderer at Berkeley:

Adults listening to children speak are usually listening to the message, just as they are when they listen to adults. Our evidence is that they comment on the form only in the case of socially marked deviations such as obscenities, lower class non-standard

TABLE 2

Characteristics of stylistic input as a function of age

\begin{tabular}{l}
\hline Stylistic Strategies \\
$\begin{array}{c}\text { MARK } \\
\text { Months) }\end{array}$
\end{tabular}


forms, and in the case of Black families, forms believed to be "country speech". (Ervin-Tripp 1971:196)

Most of the corrections I observed by mothers to the group under five focused on speech etiquette rather than grammar. For example, a child enters the room and fails to greet the other adults present "Can't you say hello"; child interrupts a conversation "Wait until I am finished" or "Say excuse me first"; child uses taboo word; child fails to maintain a civil tone when speaking to mother; child in excitement uses speech which is garbled although intelligible. (Mitchell quoted by Slobin 1969:15)

Sometimes expansion is viewed as a form of corrective feedback. In 1965, however, Cazden reported on an experimental study of the value of expansion training and found no evidence that expansions were effective. This study found that middle-class parents expanded about $30 \%$ of the speech of their children. McNeill (1970) criticized her experiment, but a careful reading of Cazden's later writings (1968) indicate that she considered her experiment inconclusive herself. Reporting on a study by Feldman and Rodgon (1970), McNeill noted that their investigation found expansion superior to modeling, the opposite of Cazden's findings. McNeill rightly concluded that the relative effectiveness of expansion and modeling remains an open question. Table 2 summarizes our knowledge of the characteristics of the stylistic input.

As the child becomes one whose remarks are worthy of interest and which justify a verbal response, a number of "verbal behavior episodes" occur between parent and child. Moerk (1972) reported on a number of such episodes stating: "In all cases there appears one problem, topic, or theme, and the interaction between mother and child proceeds smoothly until a solution is reached". The patterns Moerk described, he termed "linear interactions". One partner initiates the verbal interaction and the other responds in some way. Two possibilities exist, either the mother or the child initiates the interaction (Moerk 1972:238):

I. CHILD INITIATES CONVERSATION-MOTHER RESPONDS

\begin{tabular}{ll}
\hline $\begin{array}{l}\text { Jeffery (2.4) } \\
\text { Mother }\end{array}$ & $\begin{array}{l}\text { Cuu bir. } \\
\text { Cute birds. (Correction of Pronunciation) }\end{array}$ \\
\hline $\begin{array}{l}\text { Tiffany (3.8) } \\
\text { Mother }\end{array}$ & $\begin{array}{l}\text { Moomy, you my husband, okay? } \\
\text { I'm your husband, okay. }\end{array}$ \\
\hline
\end{tabular}

II. MOTHER INITIATES CONVERSATION-CHILD RESPONDS

Mother

Mimi (4.6)
Thank you.

Takoo. (Imitation) 
A second form of behavior, described as a "circular episode" involves two kinds of interactions: (a) The child starts, the mother responds, and the child concludes; or (b) the mother starts, the child reacts, and the mother concludes (Moerk 1972:239-240):

III. CHILD INITIATES THE INTERACTION, MOTHER RESPONDS-CHILD CONCLUDES

\begin{tabular}{ll}
$\begin{array}{l}\text { Jeanette (3.4) } \begin{array}{l}\text { Mother } \\
\text { Jeanette }\end{array} \\
\end{array}$ & $\begin{array}{l}\text { What's that? } \\
\text { That's a horse. } \\
\text { Ok, it's a horse. }\end{array}$ \\
& CHV. MOTHER INITIATES INTERACTION, \\
CHILD RESPONDS- MOTHER CONCLUDES & Mother \\
Susan (3.5) & $\begin{array}{l}\text { And then what happens? } \\
\text { (Looks thoughtful for a moment) } \\
\text { That's a long story. } \\
\text { (Laughs and hugs the child) } \\
\text { You little nut . . go on, then what } \\
\text { happened? (The child giggles and hugs } \\
\text { her book) }\end{array}$ \\
\hline
\end{tabular}

Such "linear episodes" employ a variety of strategies earlier described as prodding, expanding, modeling, and imitating. When these strategies co-occur in the verbal behavior episode, I prefer to think of them as instances of "clustering". Moerk provides several examples of combinations of several processes in one episode (1972:243):

\section{COMBINATION OF SEVERAL PROCESSES IN ONE EPISODE}

\begin{tabular}{|c|c|}
\hline Mother & $\begin{array}{l}\text { You can't grap the paint with your } \\
\text { finger. You need a what? } \\
\text { (Brown \& Hanlon would classify this } \\
\text { question as an instance of prompting). }\end{array}$ \\
\hline Bob (3.0) & Brush. \\
\hline Mother & $\begin{array}{l}\text { Can you say "paint brush"? } \\
\text { (Moerk would classify this as prodding). }\end{array}$ \\
\hline Bob & Paint brush. \\
\hline
\end{tabular}

Moerk describes numerous other interactions, one of the more interesting of which he terms "shared private speech of children and their mothers" (1972:248). Similar to what Piaget (1926), Vygotsky (1962), Flavell (1968), and Kohlberg (1968) describe as "egocentric" or "private speech", mothers apparently engage in monologue forms when in close proximity and continuous 
interaction with their infants. Moerk provides several examples (1972:248):

VI. SHARED "PRIVATE SPEECH" OF MOTHERS

\begin{tabular}{ll}
\hline Jody's (1.8) mother & $\begin{array}{l}\text { Ok, little baby, you are awful hungry } \\
\text { aren't you? Let's see, um; Jody you want } \\
\text { some-something to drink? huh? Here's } \\
\text { the rest of your eggnog. }\end{array}$ \\
\hline Jody's (1.8) mother & $\begin{array}{l}\text { All right I think I better dry it. Let me } \\
\text { wipe this, Jody, because it'll stick to the } \\
\text { wet tray.-there the tray is dry, now you } \\
\text { can put it down. }\end{array}$ \\
\hline
\end{tabular}

Although more attention needs to be focused on normal interaction between mothers and their children, the teaching strategies of imitation, prodding, expanding, and modeling, probably do not exhaust all the principles of interaction and teaching as applied by the mother. Questions as to which principles are most effective in particular situations have not even been touched upon. What is the minimum input required for a child to learn language, and how much of this input must be supplied by the mother as a critical feature of the verbal environment, are yet unanswered. Several years ago many people began to realize that the chief source of language exposure for many children was not their parents, but slightly older children. This explained why children of immigrant parents would learn the language of their community rather than, or in addition to, the language spoken at home. Thus, the parent-child language interaction may not be as critical a factor in language acquisition as previously believed.

The careful research done in the United States has assumed that the mother is the major source of input to the child in his acquisition of English. In a study involving two families, Friedlander, Jacobs, Davis, and Wetstone (1972), found that in one family $65 \%$ of the input came from the mother, $30 \%$ from the father, and $5 \%$ from guests. Percentages in the second home were mother: $59 \%$, father: $37 \%$, guests: $4 \%$. Although these similarities were noteworthy, there were striking differences. In one family $25 \%$ of the total time was taken up by the radio or television, while input from mother, father, and guests amounted to $75 \%$ of the time. The opposite pattern was observed in the second home where the television and radio were on $75 \%$ of the time and family conversation constituted the remaining 25\%. Isolated American middle class homes were mothers spend long stretches of time 
alone with their children may well be an atypical and relatively rare social situation in the world.

Jan Brukman wrote Dan Slobin (1969) in personal communication that the Koya spend most of their time with other children: "The major sources of input to Koya kids are over-whelmingly other children. Since mother and father are always working, older siblings are charged with the care of younger sibs .." (Slobin 1969:11). Keith Karnan wrote of Samoan society: “... no one adult female serves as the linguistic model for very young children as is often the case in American nuclear households... other children serve as important sources of linguistic input for the child from the time of its birth ..." (Slobin 1969:11). Ben Blount wrote of the Luo of Kenya: "After the age of 1 , an older sibling, preferably a girl between the ages of 4-11, will be assigned as a nursemaid for the child... The nursemaid continues to be the major source of speech input until the child is $3-3 \frac{1}{2}$ at which time the peer group becomes the most important source. Peer groups of this type are made up of children in the age range of $3-7 . \ldots$ From my observations, the speech input from adults seems to be quite insignificant during this period..." (Slobin 1969:12). And yet, studies on institutionalized infants and children in the United States (Brodbeck and Irvin 1946, Goldfarb 1945) confirm that verbal interaction with adults is crucial to language development, at least at early stages. Granowsky and Krossner (1970) state that serious language handicaps persist even after a child has spent eight years in a foster home. On the other hand, Lenneberg (1967:137) wrote: "Children reared in orphanages are frequently below average in speech and motor development when tested at three but when retested at six or seven are found to have caught up with the control population." Although institutional life no doubt leaves its mark on speech and language habits, little is known about the input children give one another or how much parental or adult input is necessary for normal development.

In general, there has been little systematic observation of children's speech to other children, despite observations that much language learning takes place in that context. The earliest indication in the literature of the ways in which children address one another is probably the work of Piaget (1936) and later, that of Gregoire who wrote of the didactic relationship between his sons:

Il dit au petit le nom des objects, des plantes, des animaux, etc.... Il a donc de trés fréquents occasions de lui répéter la 
formule: (C'est) une noix; (c'est) un clou; le cadet ne ferait souvent que reproduire ces leçons de vocabulaire. (1947:17)

Similarly, Berko-Gleason reported of a didactic relationship between an 8 and 4 year-old:

She wanted to give him some of her toys, and she said "Would you like to have some for you at your house?" When he agreed, she said, "Now you just carry them home, and don't run." When they got there she said: "Ricky, you want to show your mother?" You want to show your mother that you got these?" He said "Yeah. For me." And she replied, "You share them." (1973:164)

Berko-Gleason further characterized child to child speech as rich in its usage of bangs, airplane noises, chants, rhymes, use of first names, lack of endearments, and a striking amount of imitative behavior, so much that it would be considered mockery in adult speech.

In conclusion, it is clear that adults are not only sensitive to and affected by the need to communicate with their children, but that interaction patterns between parents and offspring change with the increasing language skills of the child. Yet many questions are still unresolved. Exact or even approximate parameters of just how and when sentence length and complexity changes as a function of age and yet to be thoroughly mapped. How important is parental input as opposed to input in general has yet to be evaluated, but it can be concluded that the infant is an avid learner and that he copes effectively with a variety of relatively unstructured inputs. According to Slobin, only the Mayan culture sounds somewhat similar to our American situation: "... From birth to about two years old the child is almost constantly with the mother, wrapped in swaddling cloth till about a year old, and much of the time in the sash on the mother's back.... In any case up to the age of 4 or 5 , children of both sexes receive most of their speech input from their mothers" (Slobin (1969:11). Our emphasis on the family unit seems atypical to many of the cultures around the world.

Finally, I must agree with Robin Campbell (1972) that the current neglect of environmental factors in favour of "innate ideas" has been unfortunate, for the proper course to follow in the investigation of language acquisition is to specify the nature of the linguistic environment, identify possible sources of information available to the infant, then discover which of these possible sources are used. The results of future studies like many of those discussed here may well change our total outlook on the role of 
parental input and on the process of language acquisition as a whole.

\section{REFERENCES}

Berko-Gleason, J. 1973. Code switching in children's language. In Moore, Cognitive development and the acquisition of language. New York: Academic Press.

Bever, T., Fodor, J. and Weksel, W. 1965. Theoretical notes on the acquisition of syntax: A critique of 'Contextual Generalization'. Psychological Review 72.467-82.

Blodgett, S. 1968. Language behavior as a function of social class. Thesis. Poughkeepsie, NY.: Vassar College, Department of Psychology.

Bloom, L. 1970. Language Development: Form and Function in Emerging Grammars. Cambridge: MIT Press.

Bloom, L. 1973. One Word at a Time. The Hague: Mouton.

Blount, B. G. 1972. Parental speech and language acquisition: Some Luo and Samoan examples. Anthropological Linguistics 14.119-130.

Bowerman, M. 1973. Early Syntactic Development: A Cross-Linguistic Study with Special Reference to Finnish. Cambridge: Cambridge University Press.

Braine, M. D. 1971. On two types of models for the internalization of grammars. In D. Slobin, The Ontogenesis of Grammar. New York: Academic Press.

Brodbeck, A. and Irvin, O. 1946. The speech behavior of infants without families. Child Development 17:145-156.

Broen, P. and Siegal, G. 1971. Variations in normal speech disfluencies. Language and Speech 15.219-31.

Broen, P. 1972. The verbal environment of the language-learning child. Unpublished Ph.D. dissertation. Minneapolis: University of Minnesota.

Brown, R. 1958. How shall a thing be called? Psychological Review 65.14-21.

Brown, R. 1970. The child's grammar from I to III. In R. Brown, Psycholinguistics: Selected Papers by Roger Brown. London: Free Press Paperback.

Brown, R. 1973. A First Language. Cambridge, MA.: Harvard University Press.

Brown, R. and Bellugi, U. 1964. Three processes in the child's acquisition of syntax. Harvard Educational Review 34.133-151.

Brown, R., Cazden, C. and Bellugi, U. 1969. The child's grammar from I to III. In Minnesota Symposium on Child Psychology.

Brown, R. and Fraser, C. 1964. The acquisition of syntax. In U. Bellugi and R. Brown (Eds.), The Acquisition of Language. Chicago: University of Chicago Press.

Brown, R. and Hanlon, C. 1970. Derivational complexity and order of acquisition in child speech. In J. R. Hayes, Cognition and the Development of Language. New York: Wiley \& Sons.

Brown, R., Salerno, R. A., and Sachs, J. 1972. Some Characteristics of Adult's Speech to Children. Report No. 6, Language Acquisition Laboratory, University of Connecticut.

Campbell, R. 1972. The study of language acquisition. In J. Lyons (Ed.), New Horizons in Linguistics. Baltimore: Penguin Books.

Casagrande, J. 1964. Comanche baby language. In D. Hymes (Ed.), Language in Culture and Society. New York: Harper \& Row.

Cazden, C. 1965. Environmental assistance to the child's acquisition of grammar. Unpublished Ph.D. dissertation. Cambridge: Harvard University. 
Drach, K. 1969. The language of the parent: A pilot study. In The Structure of Linguistic Input to Children, Working Paper No. 14, Language Behavior Research Laboratory, University of California, Berkeley.

Ervin-Tripp, S. M. 1970. Discourse agreement: How children answer questions. In J. R. Hayes, Congnition and the Development of Language. New York: Wiley \& Sons.

Ervin-Tripp, S. M. 1971. An overview of theories of grammatical development. In D. Slobin, The Ontogenesis of Grammar. New York: Academic Press.

Feldman, C. F. and Rodgon, M. 1970. The effects of various types of adult responses in the syntactic acquisition of two to three-year-olds. Unpublished paper. Chicago: University of Chicago, Department of Psychology.

Ferguson, C. 1964. Baby-talk in six languages. American Anthropologist 66.103-13.

Flavell, J. B. 1968. The Development of Role Taking and Communication Skills in Children. New York: Wiley \& Sons.

Fraser, C. and Roberts, N. 1975. Mother's speech to children of four different ages. Journal of Psycholinguistic Research 4.9-16.

Friedlander, B. Z., Jacobs, A. C., Davis, B. B., and Wetstone, H. S. 1972. Time sampling analysis of infant's natural language environments in the home. Child Development 43.730-740.

Goldfarb, W. 1945. Effects of psychological deprivation in infancy and subsequent stimulation. American Journal of Psychiatry 102.18-33.

Granowsky, S. and Krossner, W. J. 1970. Kindergarten teachers as models for children's speech. The Journal of Experimental Education 38.23-28.

Gregoire, A. 1947. L'Apprentissage du Langage, Vol. II. Paris: Droz.

Halliday, M. A. K. 1972. Foundations of language development: A multidisciplinary approach. Paris: Unesco.

Kagan, J. and Lewis, M. 1965. Studies of attention. Merrill-Paimer Quarterly of Behavior and Development 11.95-127.

Kernan, K. T. 1969. The acquisition of language by Samoan children. Working Paper No. 21, Language Behavior Research Laboratory, University of California, Berkeley.

Kobashigawa, B. 1969. Repetitions in a mother's speech to her child. In The Structure of Linguistic Input to Children, Working Paper No. 14, Language Behavior Research Laboratory, University of California, Berkeley.

Kohlberg, L. 1968. Private speech: Four studies and a review of theories. Child Development 39.691-736.

Labov, W. 1970. The study of language in its social context. Studium Generale 23.30-87.

Lenneberg, E. 1964. Speech as a motor skill with special reference to non-aphasic disorders. In U. Bellugi and R. Brown (Eds.), The Acquisition of Language. Chicago: University of Chicago Press.

Lenneberg, E. 1967. Biological Foundations of Language. New York: Wiley \& Sons.

Lewis, M., Kagan, J. and Campbell, H. 1966. Studies of infant attention: I. The six-month old. Unpublished manuscript. Fels Research Institute, Yellow Springs, Ohio.

MacClay, H. and Osgood, C. 1959. Hesitation phenomena in spontaneous English speech. Word 15.19-44.

McNeill, D. 1966. Developmental psycholinguistics. In F. Smith and G. Miller (Eds.), The Genesis of Language. Cambridge: MIT Press.

McNeill, D. 1968. The creation of language. In R. C. Oldfield, Language: Selected Readings. Baltimore: Penguin Books.

McNeill, D. 1970. The Acquisition of Language: The Study of Developmental Psycholinguistics. New York: Harper \& Row. 
Moerk, E. 1972. Principles of interaction in language learning. Merrill-Palmer Quarterly 18.229-259.

Moerk, E. 1974. Changes in verbal child-mother interactions with increasing language skills of the child. Journal of Psycholinguistic Research 3.101-116.

Pfuderer, C. 1969. Some suggestions for a syntactic characterization of baby talk style. The Structure of Linguistic Input to Children. Working Paper No. 14.1-20, Language Behavior Research Laboratory, University of California, Berkeley.

Phillips, J. R. 1973. Syntax and vocabulary of mothers' speech to young children. Child Development 44.182-185.

Piaget, J. 1926. The Language and Thought of a Child. New York: Harcourt-Brace.

Slobin, D. 1969. Questions of language development in cross-cultural perspective. In the Structure of Linguistic Input to Children, Working Paper No. 14, Language Behavior Research Laboratory, University of California, Berkeley.

Snow, C. 1972. Mother's speech to children learning language. Child Development 43.549-565.

Vygotsky, L. 1962. Thought and Language. Translated from the original (1934) by E. Hanfmann \& G. Vakar. Cambridge: MIT Press.

Waterson, N. 1971. Child phonology: A prosodic view. Journal of Linguistics 7.179-211. 